\title{
Assessment of Geoidal Undulation (N) Values Computed with Reference to Different Earth Gravity Models
}

\author{
Benjamin John Bulangas ${ }^{1}$, Ahmed Mohammed ${ }^{1}$, Matapa Jackson Ismaila ${ }^{1}$ \\ ${ }^{l}$ Department of Surveying and Geoinformatics, Modibbo Adama University of Technology, PMB 2076, Yola. \\ Adamawa State, Nigeria. \\ +2348065906379,jbbulangasjbb@gmail.com, ahmed4gis@gmail.com, jacksonmatapa@gmail.com
}

\begin{abstract}
This research entails the determination of the variations in global geoid undulation with reference to different Earth Gravity Models (EGMs). Geoidal undulation values of 22 points selected within the study area were determined from GPS derived data on differential mode. The undulation values were computed with reference to three different earth gravity models (EGM84, EGM96 and EGM2008) which use geopotential coefficients and spherical harmonic analysis. The results obtained were plotted and the configuration of the local geoid was obtained with respect to each gravity model. It was observed that structural development in the school (study area) since its inception in 1981 has forced some significant changes in the mass distribution in the school and consequently changes in gravity values which in turn changes the undulation values (which depends on gravity) from point to point. It was also observed that there was correlation between the local geoid determined and the nature of the topography. Areas with higher ellipsoidal or orthometric heights experience greater separation between the geoid and the ellipsoid.

Key Words: Geoid, Geoid Undulation, EGM, DGPS, Topography
\end{abstract}

\section{Introduction}

Being the physical surface of the earth, Geoid is the border between the solid or fluid masses and the atmosphere. The ocean floor is included in this formulation, being the bounding surface between the solid terrestrial body and the oceanic water masses. The irregular surface of the solid earth (continental and ocean floor topography) cannot be represented by a simple mathematical (analytical) function. It is therefore described point wise by the coordinates of control points. Given an adequately dense control network, the detailed structure of this surface can be determined by interpolation of data from terrestrial topographic and hydrographic surveying. On the other hand, the ocean surfaces (70\% of the earth's surface) are easier to represent. If we neglect the effects of ocean currents and other "disturbances", the ocean surfaces form a part of a level or equipotential surface of the earth's gravity field (surface of constant gravity potential). We may think of this surface as being extended under the continents and identify it as the mathematical figure of the earth, which can be described by a condition of equilibrium (Helmert, 1884). J. B. Listing (1873) designated this level surface as geoid.

The body of the earth and its gravity field are subject to temporal variations of secular, periodic, and abrupt nature, which can occur globally, regionally, and locally. These variations also influence the orientation of the earth. Modern geodetic measurement and evaluation techniques are used to detect these variations to a high level of accuracy. If time-independent results are required, geodetic observations must be corrected for temporal variations. By determining temporal variations, the science of geodesy contributes to the investigation of the kinematic and dynamic properties of the terrestrial body. Accordingly, the figure of the earth and the external gravity field must be considered as time dependent quantities: "Four-dimensional geodesy".

There are relationships between the topographical surface of the earth and its figures of approximations (Geoid and Ellipsoid). These relationships can be established by their height systems. The height of a point on the earth's surface measured along the ellipsoidal normal to the surface of the Ellipsoid is known as ellipsoidal height (h). The height of a point on the earth's surface measured along the plumbline, normal to the Geoid, to the surface of the Geoid is known as orthometric height $(\mathrm{H})$. Orthometric height coincides with the direction of gravity vector which is at all points normal to the surface of the Geoid. Orthometric height at every point therefore is a function of gravity at that point. The surface of the geoid is higher than the reference ellipsoid wherever there is a positive gravity anomaly and lower than the reference ellipsoid wherever there is a negative gravity anomaly. The difference between these two height systems (ellipsoidal and orthometric heights) is the Geoidal Undulation variations (See Fig. 1) that this work sought to determine in the study area. The Geoid Undulation determination in the study area is done by Global Positioning System (GPS) observations on differential mode. The geographical coordinates (Longitude, $\lambda$ and Latitude, $\phi$ ) and the ellipsoidal height, $\mathrm{h}$ has 
been obtained from DGPS observations and is used as data from which the Geoid Undulation and Orthometric height were determined. The study of the height relationships between these surfaces with reerence to various Earth Gravity Models (EGMs) will definitely lead to the determination of series of Geoidal undulations. Therefore, undulation of the Geoid is the mathematical process of determining the height in meters above the Geoid (relative to the Mean Sea Level) from height provided by the Global Positioning System (GPS) which uses the World Geodetic Survey (WGS84) ellipsoid as reference. In maps and common use the height over the Mean Sea Level is used to indicate the height of elevations while the ellipsoidal height results from the restrictions that apply for the GPS system. The process of undulation determination is not standardized, as different countries use different Mean Sea Level as reference but this study is referred to (WGS84) ellipsoid.

Separation between the geocentric reference ellipsoid and the geoid is called the geoidal height, or geoidal undulation, and is generally denoted by N. Torge, (2001) stated that if a point is located on the geoid, we obtain the geoid height, $\mathrm{N}$ (also called geoidal undulation) as the vertical distance between the ellipsoid and the geoid. A geometric definition follows by differencing the ellipsoidal height, $\mathrm{h}$ and the orthometric height, $\mathrm{H}$ as represented by equation (1):

$$
N=h-H
$$

Where $\mathrm{N}=$ Geoidal Undulation, $\mathrm{h}=$ Ellipsoidal height and $\mathrm{H}=$ Orthometric height

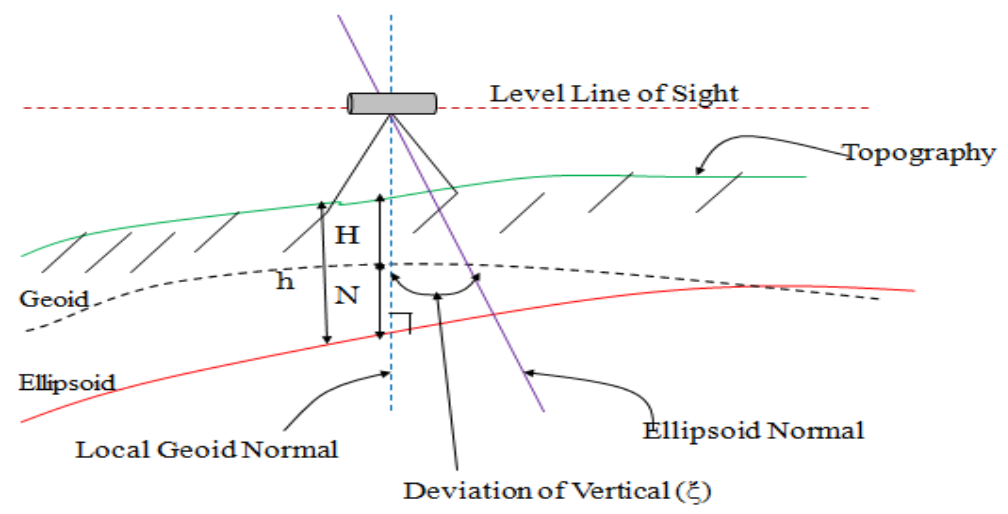

Figure 1: Relationship between Ellipsoidal and Orthometric Heights.

In recent times, the advent of the Global Positioning System (GPS) has helped tremendously in reducing the labour involved as well as in enhancing the accuracy of positioning. The GPS constitutes best known satellite navigation system that provides autonomous geo-spatial positioning with global coverage. The satellites orbiting about the centre of gravity of the earth, can only measure heights relative to a geocentric reference ellipsoid. To obtain one's geoidal undulation as to determine the geoidal height, a raw GPS reading must be converted by the use of Geoid Height Calculator/ EGM96 geoid calculator/GeoidEval Software. In this study, global geoidal undulations variations in Modibbo Adama University of Technology Yola, Adamawa State were determined through the determination of ellipsoidal coordinates of selected points using GPS observations on differential mode, determining the Geoidal Undulation and orthometric heights using Geoid Height Calculator, EGM96 Geoid Calculator and GeoidEval Calculator Software and assessing the geoidal undulation $(\mathrm{N})$ values computed with reference to different Earth Gravity Models (EGMs) over the area of survey.

\section{Study Area}

The study area covers the entire campus of Modibbo Adama University of Technology Yola, Gerei Local Government Area, Adamawa State, Nigeria. It is between longitude $12^{\circ} 29^{\prime} \mathrm{E}$ and $12^{\circ} 31^{\prime} \mathrm{E}$; latitude $9^{\circ}$ $19^{\prime} \mathrm{N}$ and $9^{\circ} 22^{\prime} \mathrm{N}$ (See Fig. 2). Some parts of the school are rocky with most of the ground covered with sandy soil of relatively flat terrain. The area studied was approximately $7.98 \mathrm{Km}^{2}$. 


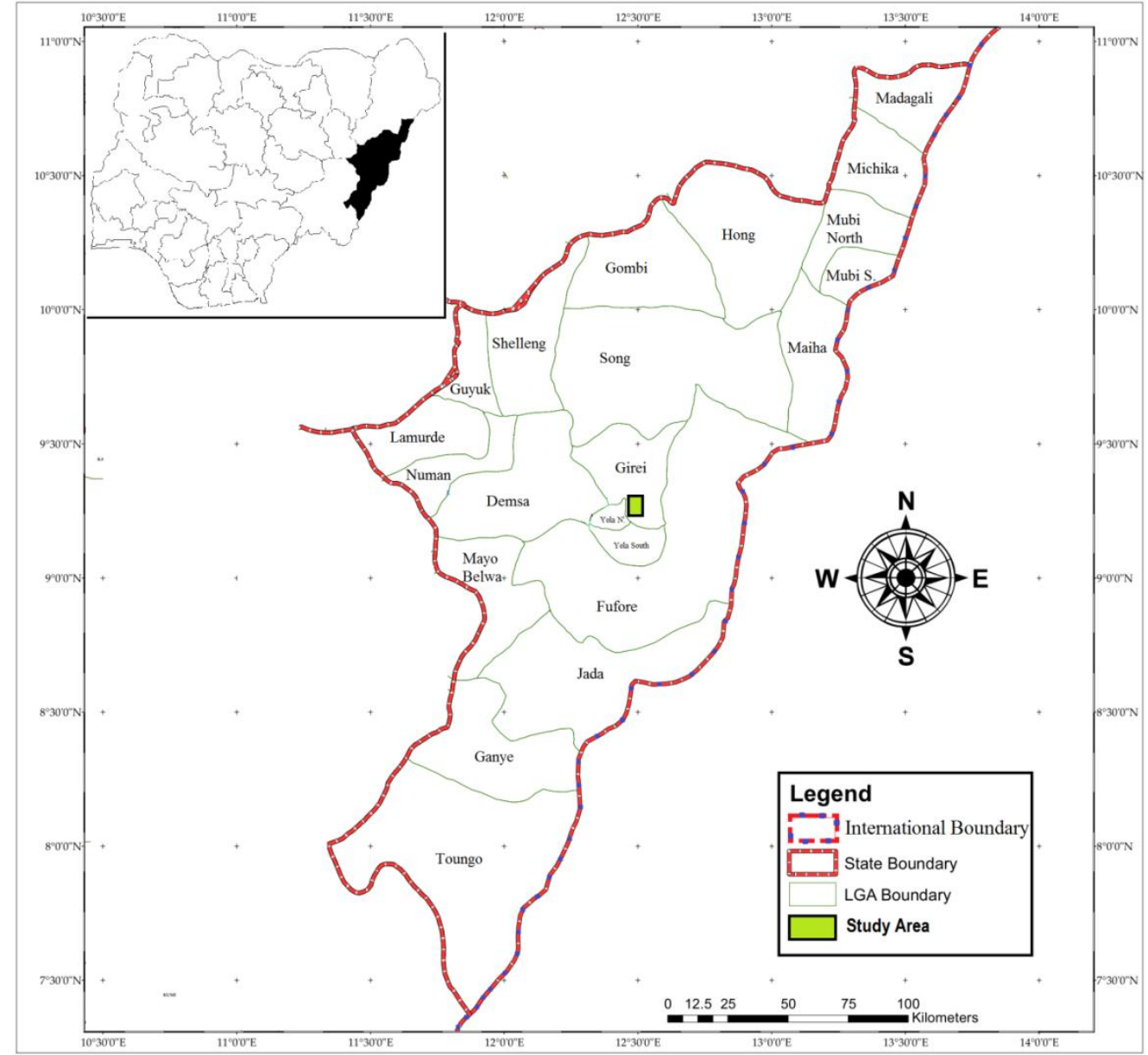

Figure 2: Adamawa State Showing the Study Area Source: Space Applications Department, NASRDA (2006)

III. Materials and Methods

Fig. 3 is the Methodology Workflow that shows step by step procedure used in the execution of this study.

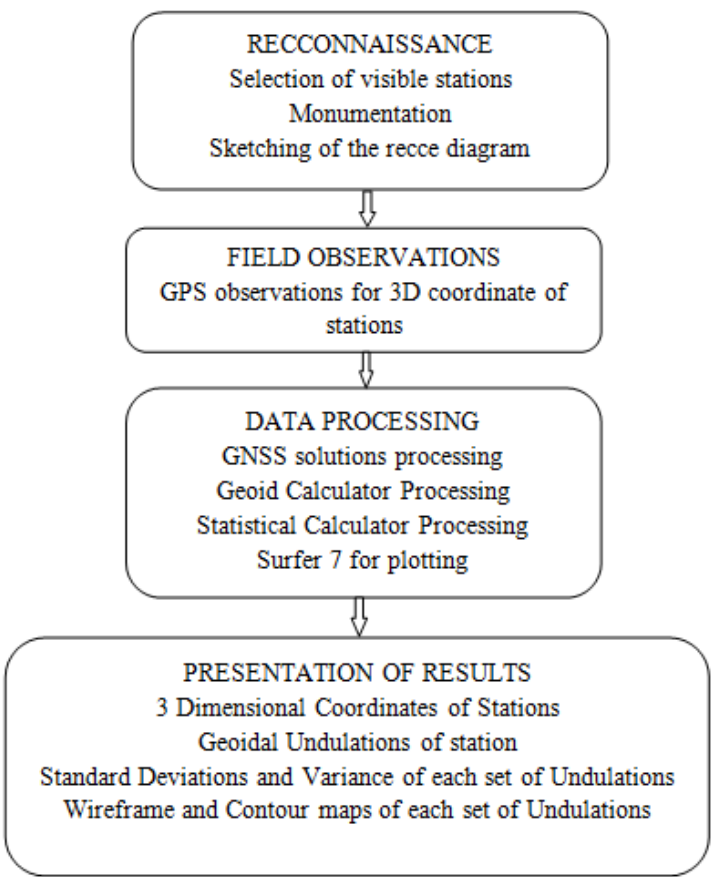

Figure 3: Methodology Workflow 


\subsection{Data Acquisition}

One of the fundamental steps to successful research work is data acquisition method related to the research. The output required depends on the input data acquired. Global Positioning System on Differential mode was used to acquire field data for this research. Twenty-two stations were marked in the study area during reconnaissance survey and thirty minutes PP (Post Processing) static rover shoots observation using ProMark 3 Differential Global Positioning System (DGPS) was carried out on all the established points with instrument on station MCP03 as shown in the Figure 3 below:

\subsection{Data Processing}

Data processing follows some basic mathematical principles even though all were carried out using software. Raw DGPS data was processed using GNSS solutions and the results obtained were imputed into geoid height calculator software and the geoidal undulations were obtained with reference to EGM96.

\subsubsection{Processing DGPS raw data using GNSS solutions}

GNSS solution is an indispensable software tool for all surveyors who need to be efficiently and smoothly assisted in their surveys. GNSS Solutions really offers high standards of performance, processing speed, compactness and flexibility. It is extremely user-friendly, simplifying many of the office tasks, a feature which will be appreciated by novice and experienced users alike. GNSS Solutions support a wide range of surveying applications, whether conducted in post-processing or real time. This work was carried out in post processing format. Raw data collected by a receiver was processed to determine the differential relationship between the points occupied during data collection. The result of processing GPS raw data is a vector defining this relationship. Computation of these vectors is the role of the data processing module within GNSS Solutions. The data processing module automatically analyzes the quality of the raw data files and adjusts processing parameters to produce the best vector possible, transferring most of the processing effort from the user to the processing software. The output results after the processing and adjustment is the coordinates of the surveyed points with their associated variances and error ellipses as shown in Fig. 4 and 5.

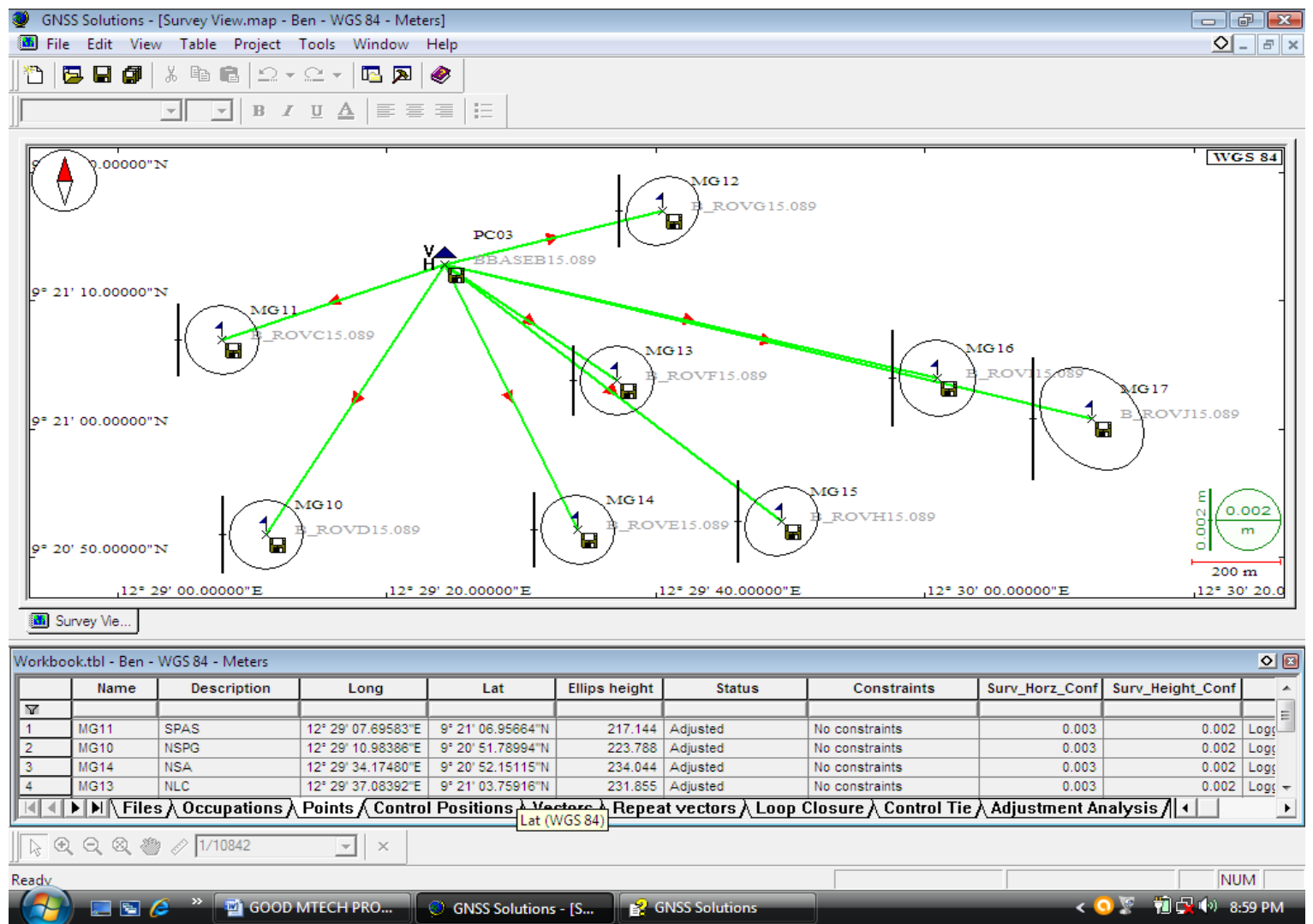

Figure 4: Processing first session of observations. 


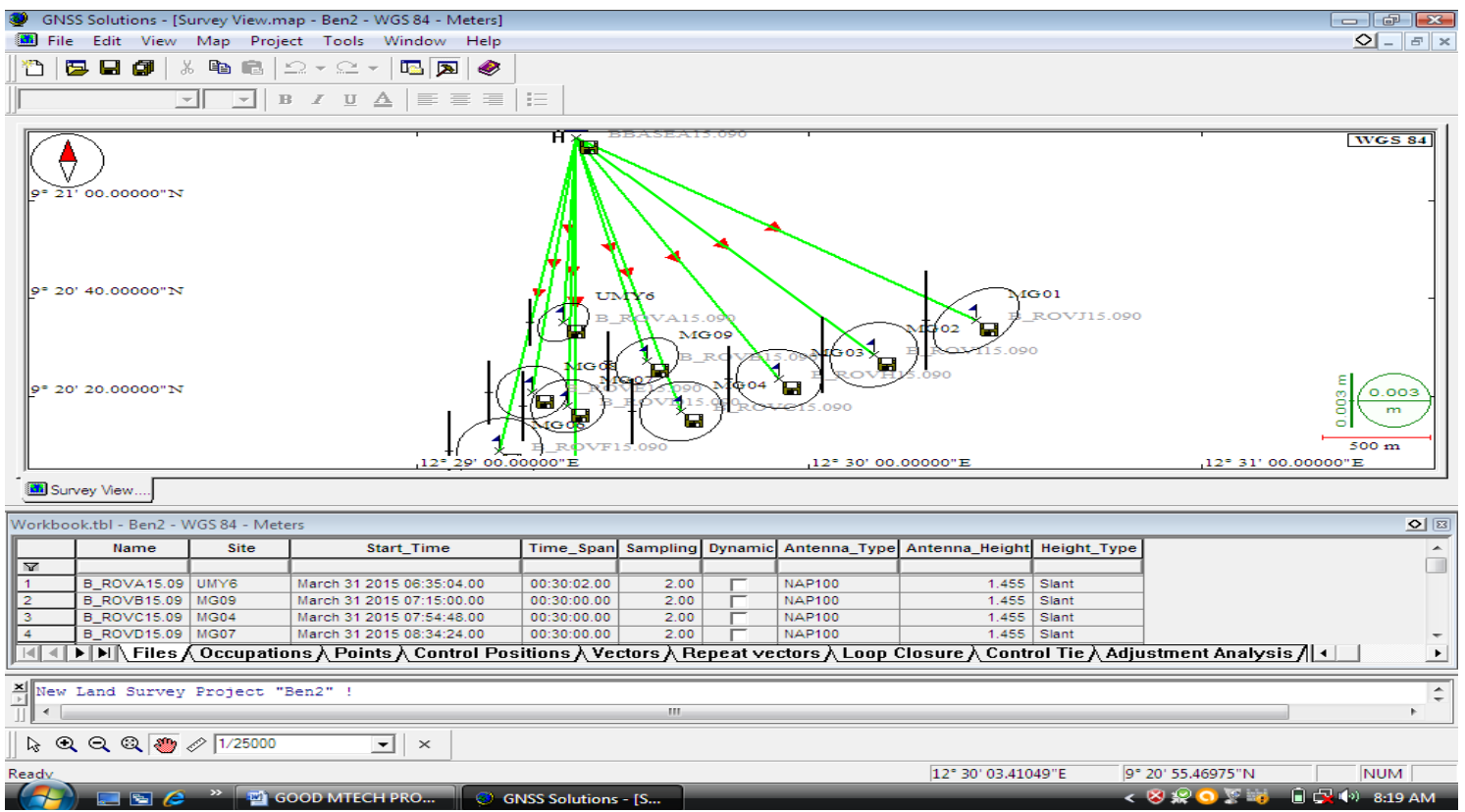

Figure 5: Processing second session of observations.

\subsubsection{Determination of geoidal undulation with reference to various EGMs}

The Geoid Height Calculator calculates a geoid undulation at a point whose latitude and longitude is specified. The program is designed to use the potential coefficient model and a set of spherical harmonic coefficients of a correction term. The correction term is composed of several different components, the primary one being the conversion of a height anomaly to a geoid undulation. The principles of this procedure were initially described by Rapp (1996). The undulation will refer to the WGS84 ellipsoid.

When the disturbing potential $\mathrm{T}$, at a point $\mathrm{P}(\phi, \lambda, r)$ on or above the earth's surface, the height anomaly $\zeta$ is then given as equation (2), (Heiskanen and Moritz, 1967).

$$
\zeta(\phi, \lambda, r)=\frac{T(\phi, \lambda, r)}{\Upsilon_{B}}
$$

Where $\mathrm{r}$ is the geocentric distance to the point, $\Upsilon_{B}$ is the value of theoretical gravity at point $\mathrm{P}$. The conversion of height anomaly to a geoid undulation is given equation (3) as:

$$
N(\phi, \lambda)=\zeta(\phi, \lambda, r)+\frac{\Delta g_{B} H}{\Upsilon}
$$

Where $\Delta g_{B}$ is the Bouguer anomaly at point $\mathrm{P}, \mathrm{H}$ is the orthometric height at point $\mathrm{P}$, and $\Upsilon$ is the average value of gravity at that point. The orthometric height can in turn be computed from equation (1). The output of computed undulations and orthometric heights with respect to the different EGMs used (EGM84 Geoid Height Calculator gives results to three decimal places, EGM96 Geoid Calculator gives results to two decimal places and GeoidEval (EGM2008) Calculator gives results to four decimal places) were presented in next section.

Different sets of geoidal undulation values computed from different Earth Gravity Models were plotted using Surfer 11 software. The 'Map' file was selected and the plotting commands were displayed. The wireframe and contour map commands were selected one after the other and the respective maps were automatically displayed.

\subsection{Statistical Testing}

\subsubsection{Standard error and standard deviation}

The standard error and standard deviation of the undulation values for each set of values was determined using statistical test calculator (STATCAL). In this, mean, unbiased standard deviation, standard error (variance) of the mean, and median were calculated. Data is entered using a standard spreadsheet interface (see Fig. 6). Finite population correction is incorporated into the calculation of the standard error of the mean, so the population size should be specified whenever the sample size is greater than ten percent of the population size. The software works on the principle that let the sample be $\mathrm{x}$ and the sample size be $\mathrm{n}$. The Mean and Standard Deviation are given by equation (4) and (5) respectively. 


$$
\begin{aligned}
& \bar{x}=\frac{\sum x}{n} . \\
& S=\sqrt{\frac{\sum(x-x)}{n-1}} .
\end{aligned} .
$$

While Variance, $\sigma=\mathrm{S}^{2}$. Results are shown in Figure 6 and Table 3.

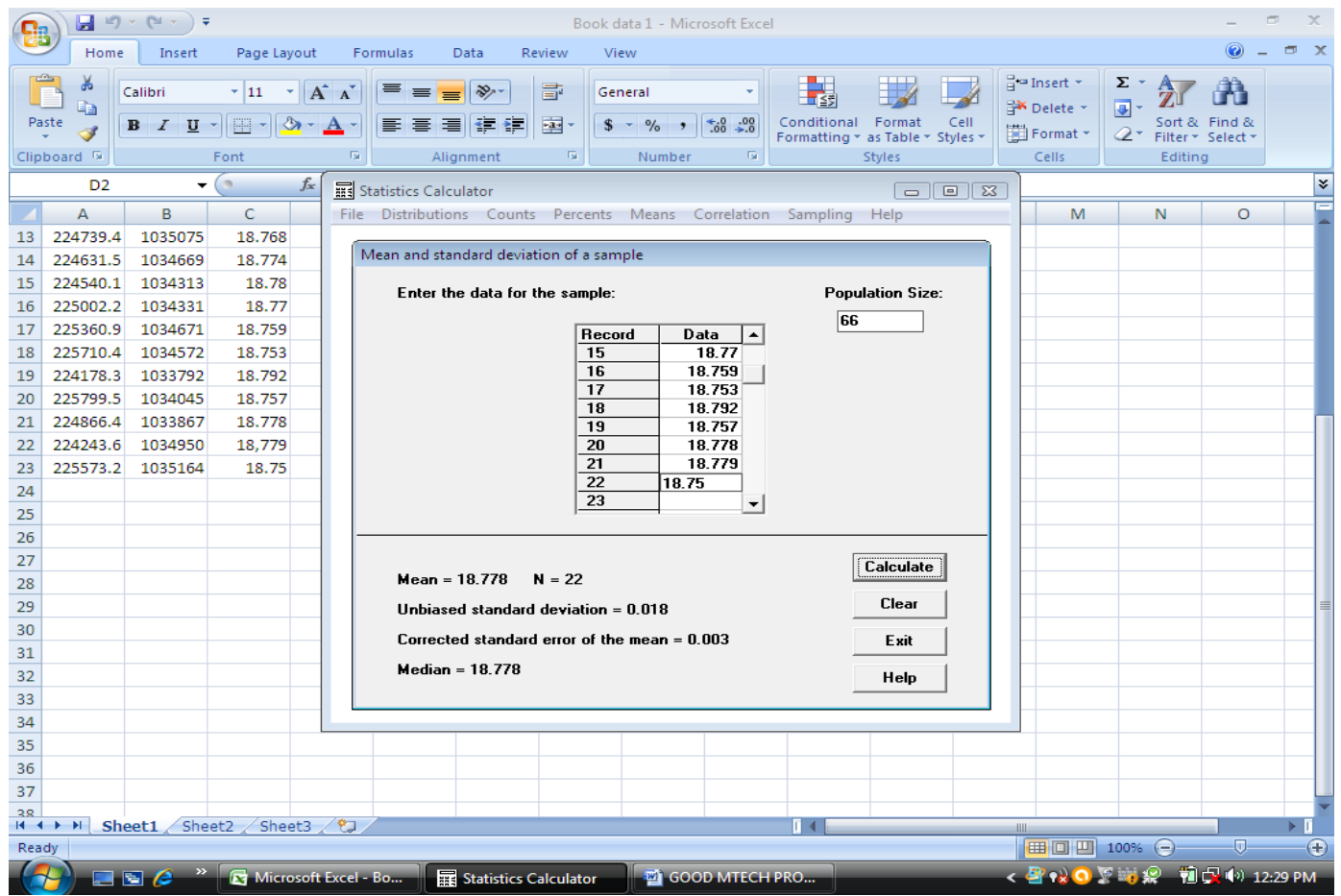

Figure 6: Window for computing standard deviation and variance of various undulations.

\subsubsection{Chi square probability test}

The chi-square is one of the most popular statistics because it is easy to calculate and interpret. Using the chi-square statistic and its associated degrees of freedom, the software reports the probability that the differences between the observed and expected frequencies occurred by chance. Generally, a probability of 0.05 or less is considered to be a significant difference. The result of this test is 0.148 which shows that the difference is not significant in the geoidal undulation values determined with respect to all earth gravity models.

\subsection{Presentation of Results}

\section{Presentation and Discussions of Results}

The results presented are the DGPS derived adjusted data (Longitude, Latitude and ellipsoidal height) of all the stations selected in the study area (Table 1), the geoidal undulation values, the ellipsoidal heights and their respective orthometric heights computed from adjusted GPS data with reference to different Earth Gravity Models (EGMs) in meters (Table 2). Table 3 shows the Standard Deviation (SD) and Variance computed from each set of geoidal undulation values determined with respect to each gravity model as well as the result from chi square probability test. Table 4 shows the geographical and Universal Transverse Mercator (UTM) coordinates of all the selected stations in the study area.

Fig. 7(a), 8(a) and 9(a) shows the wireframes of the geoidal undulation values with reference to different earth gravity models while Fig. 7(b), 8(b) and 9(b) shows the contour maps plotted from the geoidal undulation values of EGM84, EGM96 and EGM2008 models respectively. All the results presented are the true reflection of the computational processes involved in the process of geoidal undulation determination using GPS observations. Figures 7(a) to 9(b) were all plotted from the longitude, latitude and the geoidal undulation values obtained. 
Assessment of Geoidal Undulation (N) Values Computed with Reference to Different Earth Gravity..

Table 1: Adjusted Data of DGPS Observation.

\begin{tabular}{|c|c|c|c|c|c|c|}
\hline Station & $\begin{array}{l}\text { Station } \\
\text { description }\end{array}$ & Longitude & Latitude & Ellipsoidal heigl & Status & Baseline length \\
\hline MG11 & SPAS & $12^{\circ} 29^{\prime} 07.69 " \mathrm{E}$ & $9^{\circ} 21^{\prime} 06.95 " \mathrm{~N}$ & 217.14 & Adjusted & $538.656 \mathrm{~m}$ \\
\hline MG10 & NSPG & $12^{\circ} 29^{\prime} 10.98^{\prime \prime} \mathrm{E}$ & $9^{\circ} 20^{\prime} 51.78 " \mathrm{~N}$ & 223.78 & Adjusted & $764.260 \mathrm{~m}$ \\
\hline MG14 & NSA & $12^{\circ} 29^{\prime} 34.17 " \mathrm{E}$ & $9^{\circ} 20^{\prime} 52.15 " \mathrm{~N}$ & 234.04 & Adjusted & $703.359 \mathrm{~m}$ \\
\hline MG13 & NLC & $12^{\circ} 29^{\prime} 37.08^{\prime \prime E}$ & $9^{\circ} 21^{\prime} 03.75 " \mathrm{~N}$ & 231.85 & Adjusted & $479.208 \mathrm{~m}$ \\
\hline MG12 & NEC & $12^{\circ} 29^{\prime} 40.52^{\prime \prime} \mathrm{E}$ & $9^{\circ} 21^{\prime} 17.01 " \mathrm{~N}$ & 225.01 & Adjusted & $510.650 \mathrm{~m}$ \\
\hline MG15 & SMIT & $12^{\circ} 29^{\prime} 49.30^{\prime \prime} \mathrm{E}$ & $9^{\circ} 20^{\prime} 52.85 " \mathrm{~N}$ & 240.72 & Adjusted & $978.972 \mathrm{~m}$ \\
\hline MG16 & KUH & $12^{\circ} 30^{\prime} 00.96 " \mathrm{E}$ & $9^{\circ} 21^{\prime} 03.99^{\prime \prime} \mathrm{N}$ & 236.99 & Adjusted & $1150.871 \mathrm{~m}$ \\
\hline MG17 & TED & $12^{\circ} 30^{\prime} 12.44^{\prime \prime E}$ & $9^{\circ} 21^{\prime} 00.86 " \mathrm{~N}$ & 241.00 & Adjusted & $1513.992 \mathrm{~m}$ \\
\hline MCP03 & NTEB & $12^{\circ} 29^{\prime} 24.32^{\prime \prime} \mathrm{E}$ & $9^{\circ} 21^{\prime} 12.84 " \mathrm{~N}$ & 221.56 & Adjusted & Base station \\
\hline UMY6 & $\mathrm{BH}$ & $12^{\circ} 29^{\prime} 22.43^{\prime \prime} \mathrm{E}$ & $9^{\circ} 20^{\prime} 35.14 " \mathrm{~N}$ & 223.21 & Adjusted & $1159.318 \mathrm{~m}$ \\
\hline MG09 & BCA & $12^{\circ} 29^{\prime} 35.14 " \mathrm{E}$ & $9^{\circ} 20^{\prime} 27.08 " \mathrm{~N}$ & 229.92 & Adjusted & $1444.012 \mathrm{~m}$ \\
\hline MG04 & PQTS & $12^{\circ} 29^{\prime} 40.48^{\prime \prime} \mathrm{E}$ & $9^{\circ} 20^{\prime} 17.00 " \mathrm{~N}$ & 237.32 & Adjusted & $1784.965 \mathrm{~m}$ \\
\hline MG07 & CPC & $12^{\circ} 29^{\prime} 23.00 " \mathrm{E}$ & $9^{\circ} 20^{\prime} 17.92 " \mathrm{~N}$ & 232.88 & Adjusted & $1687.462 \mathrm{~m}$ \\
\hline MG08 & NNM & $12^{\circ} 29^{\prime} 17.60 " \mathrm{E}$ & $9^{\circ} 20^{\prime} 20.74 " \mathrm{~N}$ & 229.13 & Adjusted & $1613.210 \mathrm{~m}$ \\
\hline MG06 & NBM & $12^{\circ} 29^{\prime} 12.65 " \mathrm{E}$ & $9^{\circ} 20^{\prime} 08.80^{\prime \prime} \mathrm{N}$ & 234.00 & Adjusted & $1998.926 \mathrm{~m}$ \\
\hline MG05 & BMC & $12^{\circ} 29^{\prime} 24.30^{\prime \prime} \mathrm{E}$ & $9^{\circ} 19^{\prime} 50.04 " \mathrm{~N}$ & 248.26 & Adjusted & $2543.491 \mathrm{~m}$ \\
\hline MG03 & TTC & $12^{\circ} 29^{\prime} 55.38^{\prime \prime} \mathrm{E}$ & $9^{\circ} 20^{\prime} 23.62^{\prime \prime} \mathrm{N}$ & 236.83 & Adjusted & $1784.782 \mathrm{~m}$ \\
\hline MG02 & BCSQ & $12^{\circ} 30^{\prime} 09.96 " \mathrm{E}$ & $9^{\circ} 20^{\prime} 28.48 " \mathrm{~N}$ & 244.70 & Adjusted & $1948.991 \mathrm{~m}$ \\
\hline MG01 & MG & $12^{\circ} 30^{\prime} 25.56 " \mathrm{E}$ & $9^{\circ} 20^{\prime} 35.64 " \mathrm{~N}$ & 248.26 & Adjusted & $2190.861 \mathrm{~m}$ \\
\hline MCP01 & FSP & $12^{\circ} 30^{\prime} 15.47 " \mathrm{E}$ & $9^{\circ} 20^{\prime} 43.72 " \mathrm{~N}$ & 248.53 & Adjusted & $1800.189 \mathrm{~m}$ \\
\hline MCP02 & $\mathrm{CHC}$ & $12^{\circ} 29^{\prime} 44.96 " \mathrm{E}$ & $9^{\circ} 20^{\prime} 37.73 " \mathrm{~N}$ & 232.10 & Adjusted & $1249.575 \mathrm{~m}$ \\
\hline MCP04 & NPG & $12^{\circ} 30^{\prime} 07.81 " \mathrm{E}$ & $9^{\circ} 21^{\prime} 20.09^{\prime \prime} \mathrm{N}$ & 233.88 & Adjusted & $1346.743 \mathrm{~m}$ \\
\hline
\end{tabular}

Source: Extracted from DGPS processed data (2015).

Table 2: Ellipsoidal heights, Geoidal Undulations and Orthometric Heights of Stations.

\begin{tabular}{|c|c|c|c|c|c|c|c|}
\hline \multirow[b]{2}{*}{ Station } & \multirow[b]{2}{*}{$\mathbf{h}(\mathbf{m})$} & \multicolumn{2}{|c|}{ EGM84 } & \multicolumn{2}{|c|}{ EGM96 } & \multicolumn{2}{|c|}{ EGM2008 } \\
\hline & & $\mathrm{N}(\mathrm{m})$ & $\mathrm{H}(\mathrm{m})$ & $\mathrm{N}(\mathrm{m})$ & $\mathrm{H}(\mathrm{m})$ & $\mathrm{N}(\mathrm{m})$ & $\mathrm{H}(\mathrm{m})$ \\
\hline MG01 & 248.262 & 18.753 & 229.509 & 16.780 & 231.482 & 16.399 & 231.863 \\
\hline MG02 & 244.700 & 18.765 & 225.935 & 16.788 & 227.912 & 16.399 & 228.301 \\
\hline MG03 & 236.832 & 18.776 & 218.056 & 16.796 & 220.036 & 16.399 & 220.433 \\
\hline MG04 & 237.326 & 18.787 & 218.539 & 16.804 & 220.522 & 16.400 & 220.925 \\
\hline MG05 & 248.261 & 18.806 & 229.455 & 16.821 & 231.440 & 16.408 & 231.853 \\
\hline MG06 & 234.000 & 18.807 & 215.193 & 16.817 & 217.183 & 16.402 & 217.598 \\
\hline MG07 & 232.884 & 18.798 & 214.086 & 16.810 & 216.074 & 16.400 & 216.485 \\
\hline MG08 & 229.132 & 18.800 & 210.332 & 16.811 & 212.321 & 16.398 & 212.734 \\
\hline MG09 & 229.920 & 18.787 & 211.133 & 16.802 & 213.118 & 16.397 & 213.523 \\
\hline MG10 & 223.788 & 18.794 & 204.994 & 16.801 & 206.987 & 16.389 & 207.399 \\
\hline MG11 & 217.144 & 18.791 & 198.353 & 16.796 & 200.348 & 16.384 & 200.760 \\
\hline MG12 & 225.010 & 18.768 & 206.243 & 16.781 & 208.229 & 16.384 & 208.627 \\
\hline MG13 & 231.855 & 18.774 & 213.081 & 16.787 & 215.068 & 16.387 & 215.468 \\
\hline MG14 & 234.044 & 18.780 & 215.264 & 16.792 & 217.252 & 16.390 & 217.654 \\
\hline MG15 & 240.721 & 18.770 & 221.951 & 16.787 & 223.934 & 16.390 & 224.331 \\
\hline MG16 & 236.994 & 18.759 & 218.235 & 16.778 & 220.216 & 16.388 & 220.607 \\
\hline MG17 & 241.001 & 18.753 & 222.248 & 16.775 & 224.226 & 16.390 & 224.611 \\
\hline UMY6 & 223.219 & 18.792 & 204.427 & 16.803 & 206.416 & 16.394 & 206.825 \\
\hline MCP01 & 248.531 & 18.757 & 229.774 & 16.781 & 231.750 & 16.395 & 232.137 \\
\hline MCP02 & 232.102 & 18.778 & 213.324 & 16.794 & 215.308 & 16.395 & 215.707 \\
\hline MCP03 & 221.564 & 18.779 & 202.785 & 16.788 & 204.776 & 16.384 & 205.181 \\
\hline MCP04 & 233.884 & 18.750 & 215.134 & 16.770 & 217.114 & 16.385 & 217.499 \\
\hline
\end{tabular}

Source: Extracted from the results of geoidal undulation computations (2015).

Table 3: Standard Deviation and Variance of Various Sets of Undulation Values.

\begin{tabular}{|l|l|l|}
\hline & Standard deviation & Variance \\
\hline EGM84 Geoidal undulation values & 0.018 & 0.0003 \\
\hline EGM96 Geoidal undulation values & 0.014 & 0.0002 \\
\hline EGM2008 Geoidal undulation values & 0.007 & 0.0001 \\
\hline Chi Square probability test & 0.05 or less CV & 0.148 Obtained \\
\hline
\end{tabular}

Source: Compiled from statistical tests results (2015).

Table 4: Geographical and UTM Coordinates of the Stations.

\begin{tabular}{|l|l|l|l|l|}
\hline Station & Longitude $(\lambda)$ & Latitude $(\boldsymbol{\phi})$ & $\mathbf{E}(\mathbf{m})$ & $\mathbf{N}(\mathbf{m})$ \\
\hline MG01 & $12^{\circ} 30^{\prime} 25.56 " \mathrm{E}$ & $9^{\circ} 20^{\prime} 35.64^{\prime \prime} \mathrm{N}$ & 226105.47 & 1033794.42 \\
\hline MG02 & $12^{\circ} 30^{\prime} 09.96^{\prime \prime} \mathrm{E}$ & $9^{\circ} 20^{\prime} 28.48^{\prime \prime} \mathrm{N}$ & 225627.94 & 1033577.41 \\
\hline MG03 & $12^{\circ} 29^{\prime} 55.38^{\prime \prime} \mathrm{E}$ & $9^{\circ} 20^{\prime} 23.62 " \mathrm{~N}$ & 225181.75 & 1033431.19 \\
\hline MG04 & $12^{\circ} 29^{\prime} 40.48^{\prime \prime} \mathrm{E}$ & $9^{\circ} 20^{\prime} 17.00^{\prime \prime} \mathrm{N}$ & 224725.39 & 1033230.94 \\
\hline MG05 & $12^{\circ} 29^{\prime} 24.30^{\prime \prime} \mathrm{E}$ & $9^{\circ} 19^{\prime} 50.04^{\prime \prime} \mathrm{N}$ & 224225.51 & 1032406.11 \\
\hline
\end{tabular}

DOI: $10.9790 / 2402-1106036472 \quad$ www.iosrjournals.org 
Assessment of Geoidal Undulation (N) Values Computed with Reference to Different Earth Gravity ..

\begin{tabular}{|c|c|c|c|c|}
\hline MG06 & $12^{\circ} 29^{\prime} 12.65^{\prime \prime} \mathrm{E}$ & $9^{\circ} 20^{\prime} 08.80^{\prime \prime} \mathrm{N}$ & 223873.61 & 1032985.26 \\
\hline MG07 & $12^{\circ} 29^{\prime} 23.00^{\prime \prime} \mathrm{E}$ & $9^{\circ} 20^{\prime} 17.92^{\prime \prime} \mathrm{N}$ & 224191.91 & 1033263.01 \\
\hline MG08 & $12^{\circ} 29^{\prime} 17.60 " \mathrm{E}$ & $9^{\circ} 20^{\prime} 20.74 " \mathrm{~N}$ & 224027.35 & 1033351.17 \\
\hline MG09 & $12^{\circ} 29^{\prime} 35.14^{\prime \prime E}$ & $9^{\circ} 20^{\prime} 27.08^{\prime \prime} \mathrm{N}$ & 224564.55 & 1033541.92 \\
\hline MG10 & $12^{\circ} 29^{\prime} 10.98^{\prime \prime} \mathrm{E}$ & $9^{\circ} 20^{\prime} 51.78^{\prime \prime} \mathrm{N}$ & 223832.03 & 1034306.67 \\
\hline MG11 & $12^{\circ} 29^{\prime} 07.69^{\prime \prime} \mathrm{E}$ & $9^{\circ} 21^{\prime} 06.95 " \mathrm{~N}$ & 223735.22 & 1034773.65 \\
\hline MG12 & $12^{\circ} 29^{\prime} 40.52^{\prime \prime} \mathrm{E}$ & $9^{\circ} 21^{\prime} 17.01 " \mathrm{~N}$ & 224739.41 & 1035075.42 \\
\hline MG13 & $12^{\circ} 29^{\prime} 37.08^{\prime \prime E}$ & $9^{\circ} 21^{\prime} 03.75 " \mathrm{~N}$ & 224631.49 & 1034668.91 \\
\hline MG14 & $12^{\circ} 29^{\prime} 34.17 " \mathrm{E}$ & $9^{\circ} 20^{\prime} 52.15 " \mathrm{~N}$ & 224540.11 & 1034312.69 \\
\hline MG15 & $12^{\circ} 29^{\prime} 49.30^{\prime \prime} \mathrm{E}$ & $9^{\circ} 20^{\prime} 52.85 " \mathrm{~N}$ & 225002.19 & 1034331.23 \\
\hline MG16 & $12^{\circ} 30^{\prime} 00.96^{\prime \prime} \mathrm{E}$ & $9^{\circ} 21^{\prime} 03.99 " \mathrm{~N}$ & 225360.91 & 1034671.10 \\
\hline MG17 & $12^{\circ} 30^{\prime} 12.44 " \mathrm{E}$ & $9^{\circ} 21^{\prime} 00.86^{\prime \prime} \mathrm{N}$ & 225710.40 & 1034572.42 \\
\hline UMY6 & $12^{\circ} 29^{\prime} 22.43^{\prime \prime} \mathrm{E}$ & $9^{\circ} 20^{\prime} 35.14 " \mathrm{~N}$ & 224178.27 & 1033792.42 \\
\hline MCP01 & $12^{\circ} 30^{\prime} 15.47^{\prime \prime E}$ & $9^{\circ} 20^{\prime} 43.72 " \mathrm{~N}$ & 225799.48 & 1034044.95 \\
\hline MCP02 & $12^{\circ} 29^{\prime} 44.96 " \mathrm{E}$ & $9^{\circ} 20^{\prime} 37.73 " \mathrm{~N}$ & 224866.39 & 1033867.14 \\
\hline MCP03 & $12^{\circ} 29^{\prime} 24.32 " \mathrm{E}$ & $9^{\circ} 21^{\prime} 12.84 " \mathrm{~N}$ & 224243.61 & 1034950.46 \\
\hline MCP04 & $12^{\circ} 30^{\prime} 07.81^{\prime \prime E}$ & $9^{\circ} 21^{\prime} 20.09 " \mathrm{~N}$ & 225573.24 & 1035164.47 \\
\hline
\end{tabular}

Source: Compiled from results of conversion from geographical to UTM coordinates (2015).

\subsection{Discussion of Results}

The geoidal undulation values in the study area are all positive and the implication is that the geoid at all points is above the ellipsoid. This result is seen to be the consequence of two possible factors: The geoid is affected by the distribution of mass of land above Mean Sea Level and the elevated area whose centre of gravity is outside the ellipsoid causes an upward attraction leading to local elevation of the geoid above the ellipsoid.

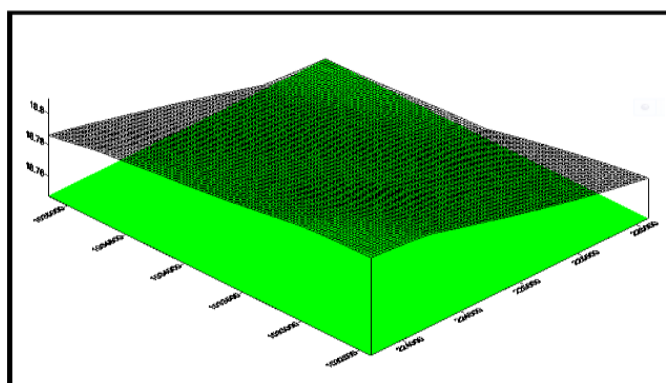

Figure 7 (a): Wireframe of EGM84 geoidal undulation values

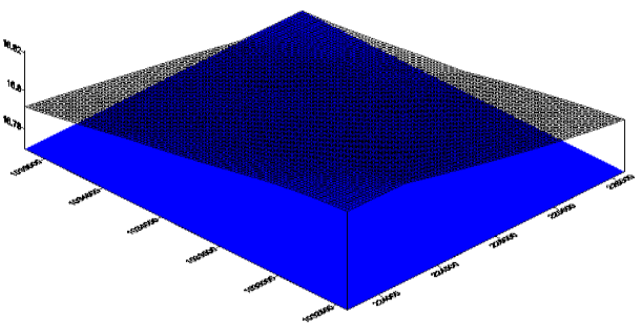

Figure 8 (a): Wireframe of EGM96 geoidal undulation value

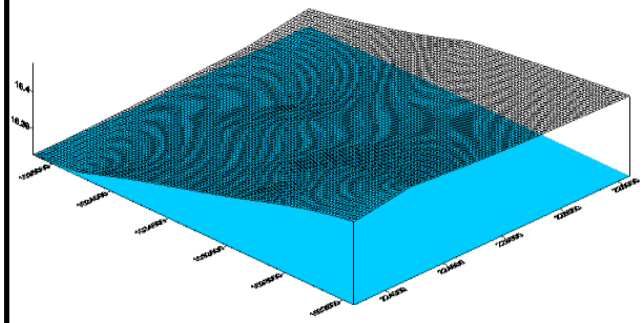

Figure 9 (a): Wireframe of EGM2008 geoidal undulation values
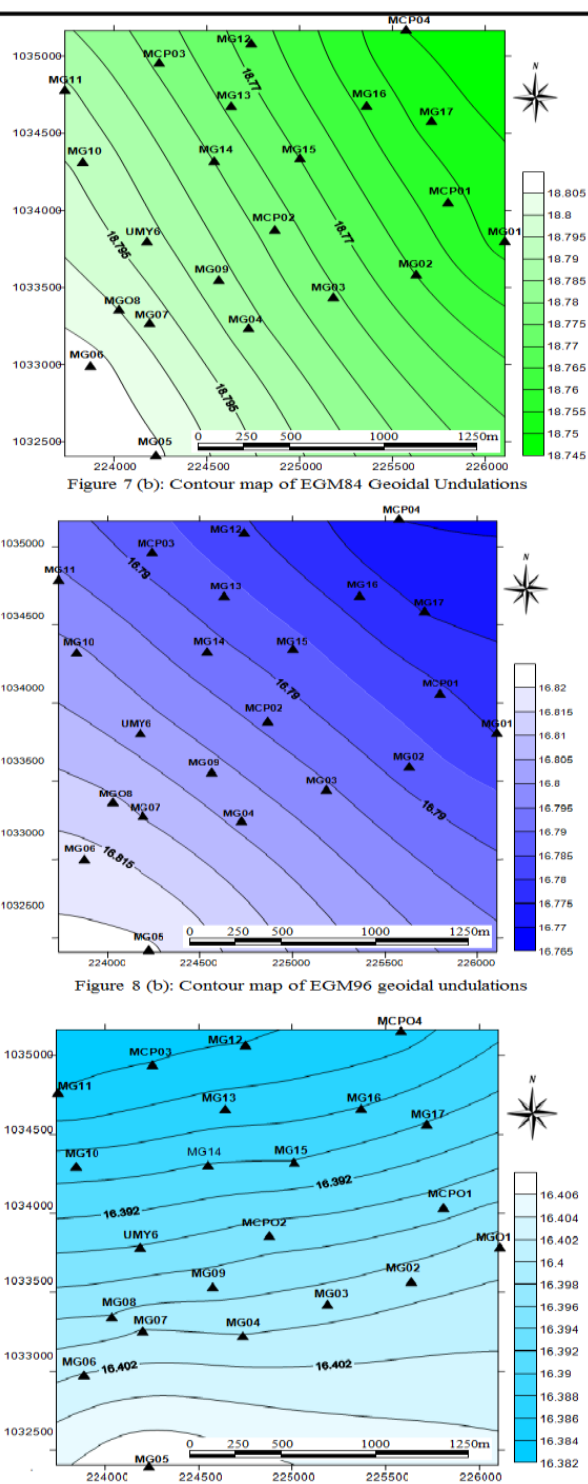

Figure 9 (b): Contour map of EGM2008 geoidal undulation 
The other factor is that the mass excess under the ellipsoid forces equipotential surface (geoid) to warp upward which gives positive geoid undulation over mass excess under the ellipsoid. The geoid undulation in the study area is affected by relatively flat topography and the heterogeneous mass distribution of the earth surface due to developmental changes in the school since its inception in 1981. As structural development increases in the school, the mass distribution changes and consequently the gravity values at different points.

The geoidal undulation value at a point which is a function of gravity at that point also changes as a function of time. This can be observed from Fig. 7(a), 8(a) and 9(a) where wireframe plotted from geoidal undulation values of different earth gravity models of different degrees and order of accuracy (EGM84, EGM96 and EGM2008) shows significant changes with respect to time as well as differences in accuracy between the EGMs due to changes in gravity. EGM96 is better than EGM84 and EGM2008 is better than EGM96. The contour maps (Fig. 7(b), 8(b) and 9(b)) of these undulations values across EGM documentations show the changes in slope directions as the shape of the geoid changes.

EGM2008 referred to the WGS84 has been found to be the most suitable gravity model for computation of geoidal undulation values of selected stations due to the fact that additional spherical harmonic coefficients has been added extending to degree 2190 and order 2159. This made the model suitable for the study of long or short wavelength of the geoidal undulation values. This claim can be verified from Table 3 where the variance of EGM 2008 set of geoidal undulation values (0.001) is the smallest among the three variances. Also from Table 2, the average difference between EGM84 and EGM96 geoidal undulation is 2 metres but the difference between EGM96 and EGM2008 is $0.4 \mathrm{~m}$ across 12 years difference each. These changes attest to the fact that geoid changes as the mass of land above Mean Sea Level experience changes as a result of natural changes and man's activity. The geoid undulation shows decrease in the study area from average of $18.7784 \mathrm{~m}$ to $16.7937 \mathrm{~m}$ in 12 years period and further decreased from $16.7937 \mathrm{~m}$ to $16.3935 \mathrm{~m}$ over the same period.

\section{Conclusion and Recommendations}

From the result obtained from this study, it was observed that the local geoidal undulation values in Modibbo Adama University of Technology Yola are all positive in conformity with the previous works carried out which states that "the geoid undulations determined for Nigeria are all positive". Significant changes were observed between the undulation values with respect to EGM84 and EGM2008. The average difference between EGM84 and EGM96 undulation values is about $2 \mathrm{~m}$ across the area of survey while the average difference between EGM96 and EGM2008 is $0.4 \mathrm{~m}$, owing to the refinement of the earth gravity model to higher degree and order of accuracy. It was also observed that geodesy has evolved from determining three dimensional parameters to what is known as "four dimensional geodesy". This is due to the daily changes in its parameters resulting from physical changes experienced on the earth surface. Time therefore has become an important Parameter in geodesy where it seeks to determine longitude $(\lambda)$, latitude $(\phi)$, height $(\mathrm{h})$ and time $(\mathrm{t})$ to define the figure of the earth. Geoid therefore is undulating in form and its shape changes as time changes.

Geoidal undulation and Orthometric height determination using Geoid Calculator Software packages is therefore recommended over expensive and time consuming conventional method of geodetic leveling and gravity measurement due to its simplified approach to data collection, processing and analysis.

\section{References}

[1]. Heiskanen, W. A. and Moritz, H. (1967): Physical Geodesy. W. H. Freeman and Company, San Francisco and London.

[2]. Helmet, F.R. (1880) Die Mathematicshen und PhysikalischenTheorien der HöherenGeodâsie. Teubner, Leipzig (reprint Minerva GmbH, Frankfurt a.m.

[3]. Listing, J. B. (1873): ÜberUnsereJetzigeKenntnis der Gestalt und Gröpe der Erde. Nachr.d.Kgl. Gesellsch.d. Wiss Und der Georg August - Univ., GöHingen.

[4]. Rapp, R. H. (1996): Use of Potential Coefficient Models for Geoid Undulation Determination Using a Spherical Harmonic Representation of the Height Anomaly/Geoid Undulation Difference, Journal of Geodesy. Volume 71, Issue 5, pp 282-289

[5]. Torge, W. (2001): Geodesy $3^{\text {rd }}$ Edition Walter de Gruyter. New York. Wichmann, Karlsruhe. 